\title{
Genetic Testing Awareness and Attitudes among Latinos: Exploring Shared Perceptions and Gender-Based Differences
}

\author{
Jada G. Hamilton ${ }^{\mathrm{a}} \quad$ Elyse Shuk $^{\mathrm{a}} \quad$ Guedy Arniellad $^{\mathrm{d}}$ C. Javier González ${ }^{\mathrm{b}}$ \\ Geoffrey S. Gold ${ }^{\mathrm{e}}$ Francesca Gany ${ }^{\mathrm{b}}$ Mark E. Robson ${ }^{\mathrm{c}}$ Jennifer L. Hay ${ }^{\mathrm{a}}$ \\ ${ }^{a}$ Behavioral Sciences Service and ${ }^{b}$ Immigrant Health and Cancer Disparities Service, Department of Psychiatry and \\ Behavioral Sciences, Memorial Sloan Kettering Cancer Center, ${ }^{c}$ Clinical Genetics Service, Department of Medicine, \\ Memorial Sloan Kettering Cancer Center, and ${ }^{\mathrm{d}}$ Harlem Residency in Family Medicine, The Institute for Family Health, \\ New York, N.Y., and eDepartment of Psychology, Hofstra University, Hempstead, N.Y., USA
}

\section{Key Words \\ Genetic testing · Hispanic · Latino - Qualitative research · \\ Skin cancer}

\begin{abstract}
Background: Latinos, whose views are infrequently examined in genomic research, may be at risk of missing out on the benefits of genomic medicine. Aims: To explore this possibility, we conducted a qualitative study of awareness and attitudes about genetic testing among Latinos with lower acculturation in New York City. Methods: We conducted four focus groups (7 English-speaking men, 5 Spanish-speaking men, 13 English-speaking women and 13 Spanish-speaking women) to explore factors that influence the adoption of new innovations through the discussion of genetic testing in general, and a hypothetical vignette describing a genetic test for skin cancer risk, in particular. Results: Through inductive thematic text analysis of focus group transcripts, our multidisciplinary team identified themes within knowledge and attitudes, communication and sources of information, anticipated responses, factors that may increase adoption, and barriers to adoption of genetic testing. Specifically, a majority of participants expressed some degree of uncertainty regarding the purpose of genetic tests and informa-
\end{abstract}

tion these tests provide, rarely discussed genetic testing with others in their social networks, and expressed concerns about the misuse of and possible adverse emotional responses to genetic information. However, participants also expressed high levels of interest in receiving a skin cancer genetic test in response to the vignette and believed that receiving actionable health information was a primary reason to consider testing. Gender-based differences in perceived barriers to testing emerged. Conclusions: The results highlight beliefs and barriers that future interventions could target to help ensure that Latinos have adequate understanding of and access to genomic medicine advances.

(c) 2015 S. Karger AG, Basel

\section{Introduction}

Advances in gene sequencing technologies have created exceptional opportunities for the delivery of personalized medical care. Clinical genetic and genomic testing can identify gene variants that are associated with risks for a number of diseases and health conditions. These tests provide risk information that can guide decisions regarding disease prevention, diagnosis and treatment for individuals seeking testing and their families. There has

\section{KARGER}

(c) 2015 S. Karger AG, Basel

$1662-4246 / 15 / 0191-0034 \$ 39.50 / 0$

E-Mail karger@karger.com

www.karger.com/phg
Jada G. Hamilton

Memorial Sloan Kettering Cancer Center

641 Lexington Avenue, 7 th floor

New York, NY 10022 (USA)

E-Mail hamiltoj@mskcc.org 
also been an upsurge in the availability of direct-to-consumer (DTC) genetic tests that predict risks for multiple common diseases and traits, and are advertised and sold directly to the general public, typically without the involvement of a healthcare provider [1]. It is expected that these applications of genomic medicine will allow for substantial improvements in health outcomes, including reduced morbidity and mortality.

Although much enthusiasm exists for the burgeoning field of genomic medicine, it is possible that the resulting health benefits will not be experienced equally by all members of society. Individuals of Latino or Hispanic ethnicity (hereafter referred to as Latinos or Latinas) are diverse in their country of origin, language preferences, education, religious beliefs and race. Latinos comprise $17 \%$ of the U.S. population and, as the fastest-growing demographic group in this country, are projected to comprise $31 \%$ of the population by 2060 [2]; yet, to date, their views have been infrequently explored in genomic research. Consequently, Latinos are at risk of missing out on the health benefits of genomic medicine - a prospect that is particularly troubling given that Latinos already experience a number of health-related disparities. For example, approximately $24 \%$ of Latinos lack health insurance, a rate higher than that of any other racial or ethnic group [3]. In addition, many Latinos lack access to a usual source of healthcare, with $27 \%$ of Latino adults reporting no usual source of care as compared to $16 \%$ of Black adults and $14 \%$ of Caucasian adults [4]. Latinos also experience lower household incomes and higher rates of poverty than do Caucasians [5]. These disparities in insurance coverage, healthcare access and income contribute to adverse health outcomes among Latinos, such as those observed in the context of cancer. Cancer surpasses cardiovascular disease as the leading cause of death among Latinos [6]. Latinos tend to have lower incidence and mortality rates for many common cancers (e.g. breast, lung, prostate) compared to Caucasians, but higher rates for acute lymphocytic leukemia, cervical, gallbladder, liver and stomach cancers $[7,8]$. In addition, for cancers including breast, lung, colorectal and melanoma, Latinos are less likely than Caucasians to be diagnosed at an early stage of disease, which may be partially explained by suboptimal rates of cancer screening [8].

Genetic testing can inform cancer screening and prevention efforts by identifying individuals at elevated risk for the development of cancer; therefore, genetic testing has the potential to improve cancer-related outcomes among Latinos. A small body of literature has begun to examine Latinos' experiences and perspectives regarding

Latinos' Genetic Testing Attitudes genetic testing. The uptake of genetic testing among Latinos appears to be low; for example, Latinas comprised only $4.2 \%$ of the women tested for the BRCA1/2 gene mutations associated with hereditary breast and ovarian cancer from 1996 to 2006 [9]. In addition, low levels of awareness and knowledge about genetic testing for cancer risk among Latinos have been reported in population-based studies [10], studies of community members [11, 12] and studies of women at high risk for hereditary breast and ovarian cancer [13-15]. In spite of their limited exposure to genetic testing, Latinos appear to have an interest in and favorable attitudes regarding genetic testing [12, 15-20].

Taken together, these findings suggest that Latinos could benefit from, and may be receptive to, efforts to increase their understanding and adoption of genomic medicine. However, in order to develop maximally effective educational and intervention efforts, additional studies are needed that explore the diverse perspectives of these individuals. In particular, there is need for research that examines the perspectives of Latino men, who have generally been excluded from past studies given their emphasis on genetic testing for hereditary breast and ovarian cancer among women. It is also important to consider the perspectives of Latinos with lower levels of acculturation (defined as the process by which individuals adopt the beliefs, values and behaviors of another culture and frequently assessed with measures of language preference, nativity and time in the U.S.) [21], given that lower awareness of, and exposure to, genetic testing for cancer may be most prominent in those with lower levels of acculturation [22-24].

The present study was designed to address these gaps and to thereby provide knowledge necessary for developing strategies to promote the equitable translation of genomic medicine advances. Guided by the Diffusion of Innovations model [25], a theoretical framework which identifies individual-level factors including knowledge, anticipated responses, barriers and communication channels that contribute to the adoption of a novel technology, we conducted a qualitative study of genetic testing awareness and attitudes among a diverse sample of Latinos in New York City. We conducted focus groups with English- and Spanish-speaking female and male Latinos in order to assess participants' perspectives regarding genetic testing in general as well as genetic testing to identify an individual's risk for skin cancer. We focused on skin cancer because of the increasing incidence of melanoma in Latinos over recent years [26-29], the tendency for melanoma to be diagnosed at a later stage in Latinos [8, 28 ] and because of their generally low awareness of the health threat posed by melanoma [30-34]. 


\section{Methods}

\section{Sample}

With approval from our Institutional Review Board, focus groups were conducted with four distinct participant groups that varied by language preference and gender: (1) English-speaking male Latinos, (2) Spanish-speaking male Latinos, (3) Englishspeaking female Latinas and (4) Spanish-speaking female Latinas. Our collaborator from a community health organization based in Harlem, NY (G.A.) facilitated study recruitment by enlisting staff at another local community-based health services organization with a mission to provide supportive services to a primarily newimmigrant, Latino population to perform the focus group recruitment. Individuals were eligible for participation if they self-identified as Latino or Hispanic, were fluent in either Spanish or English and ages 18 years or older.

Guidelines from a qualitative research tradition were utilized to design the study sampling plan and size [35-37]. First, we employed a purposive sampling strategy [38], segmenting participants by gender and language preference because we hypothesized that these factors may influence individuals' attitudes and knowledge about genetic testing; we also sought to attain a broad and varied understanding of perspectives regarding genetic testing among a Latino population. Second, as our research was exploratory, we did not aim to produce statistical generalizations from our findings. Rather, our intent was to generate detailed descriptive findings from a small set of participants upon which we may be able to formulate hypotheses which subsequently may be examined in larger studies.

\section{Recruitment Strategy}

Our community-based study collaborator (G.A.), an expert in minority recruitment with community-based organizations [39], worked with the program director at the Harlem community health services organization to facilitate the recruitment process, post flyers describing the focus groups at the organization, and verbally advertise the groups during various parenting support and child/mother interaction groups held with the organization's clients. Interested individuals approached the program director or the organization's staff to express their interest in participating. Each participant received USD 25 for their time and valued contributions.

\section{Data Collection}

According to established focus group moderation standards and practices $[35,40]$, our community-based study collaborator (G.A.) moderated the two focus groups conducted with female Latinas, and a representative from our institution's immigrant health and cancer disparities service (C.J.G.) moderated the two focus groups conducted with male Latinos. Both moderators were fluent in Spanish. A study staff member also attended and took notes during the focus groups. The research team developed a focus group guide - a uniform set of open-ended questions and discussion prompts - to facilitate the discussions (see online suppl. material, www.karger.com/doi/10.1159/000441552). The discussion topics were informed by the Diffusion of Innovations model [25] and were designed to assess participants' perceptions and beliefs regarding genetic testing, knowledge of genetic testing, sources of information regarding genetic testing, the extent of communication about genetic testing with others, whether they had consid- ered genetic testing in the past, and advantages and drawbacks of obtaining genetic testing. We also presented participants with a vignette in which we asked them to indicate their interest in obtaining a hypothetical genetic test that would assess individual risk for skin cancer. Each group session lasted approximately $90 \mathrm{~min}$. All discussions were audio-recorded and transcribed (those conducted in Spanish were translated into English) for subsequent analysis. At the end of each focus group, participants completed questionnaires assessing basic demographic characteristics (age, education, annual income, country of birth, marital status) and level of acculturation (measured with four items regarding language use and preferences; items were rated on a scale ranging from 1 to 5 and summed, with higher scores indicating greater levels of acculturation) [41, 42].

\section{Qualitative Analysis}

Participants' narrative comments were reviewed using inductive thematic text analysis, an iterative process of transcript review, interpretation and consensus discussions [43-48]. The analysis team consisted of two health psychologists (J.L.H., J.G.H.), our community-based collaborator (G.A.), a representative from our institution's immigrant health and cancer disparities service (C.J.G.), a qualitative methods specialist (E.S.) and a research study assistant (G.S.G.). Initially, each member read the same transcript, highlighting important content and recording reflections on the transcript in a process known as margin coding [49], prior to completing a written analysis template with supporting participant quotations. The entire team met to generate collective findings for each transcript by consensus, and met again to identify thematic similarities and differences between the four focus groups according to gender and language preference. As per standard procedures, the final analytic phase entailed generating higher-order descriptive and interpretive themes that represented prominent findings observed across the majority of focus groups.

\section{Results}

\section{Demographic Characteristics}

Thirty-eight individuals participated in the focus groups (7 English-speaking male Latinos, 5 Spanishspeaking male Latinos, 13 English-speaking female Latinas and 13 Spanish-speaking female Latinas). The characteristics of the participants in each focus group are presented in table 1. Individuals in the English-speaking male focus group reported the highest levels of education and income; conversely, participants in the other three focus groups had lower levels of education and income, with the majority attaining the level of high school graduate/GED or less education and reporting annual incomes of USD 29,999 or less. The majority of participants in these three focus groups had also been born outside of the U.S. Although study participants reported relatively low levels of acculturation (sample mean 8.5, scale range 4-20), a one-way between-subjects ANOVA with post- 
Table 1. Characteristics of the participants

\begin{tabular}{|c|c|c|c|c|c|}
\hline & $\begin{array}{l}\text { Total } \\
\text { sample } \\
(\mathrm{n}=38)\end{array}$ & $\begin{array}{l}\text { English- } \\
\text { speaking M } \\
(\mathrm{n}=7)\end{array}$ & $\begin{array}{l}\text { Spanish- } \\
\text { speaking M } \\
(\mathrm{n}=5)\end{array}$ & $\begin{array}{l}\text { English- } \\
\text { speaking F } \\
(\mathrm{n}=13)\end{array}$ & $\begin{array}{l}\text { Spanish- } \\
\text { speaking F } \\
(\mathrm{n}=13)\end{array}$ \\
\hline \multicolumn{6}{|l|}{ Education, $n(\%)$} \\
\hline Less than 7 th grade & $10(26.6)$ & $0(0)$ & $1(20.0)$ & $1(7.7)$ & $8(61.5)$ \\
\hline High school graduate or GED & $6(15.8)$ & $0(0)$ & $0(0)$ & $5(38.5)$ & $1(7.7)$ \\
\hline Partial college or vocational training & $8(21.1)$ & $4(57.1)$ & $2(40.0)$ & $1(7.7)$ & $1(7.7)$ \\
\hline College graduate & $2(5.3)$ & $1(14.3)$ & $0(0)$ & $1(7.7)$ & $0(0)$ \\
\hline Graduate degree or professional training & $3(7.9)$ & $1(14.3)$ & $0(0)$ & $1(7.7)$ & $1(7.7)$ \\
\hline \multicolumn{6}{|l|}{ Annual household income, $n(\%)$} \\
\hline USD 70,000-89,999 & $2(5.3)$ & $2(28.6)$ & $0(0)$ & $0(0)$ & $0(0)$ \\
\hline \multicolumn{6}{|l|}{ Country of birth, $n(\%)$} \\
\hline Continental US & $4(10.5)$ & $2(28.6)$ & $0(0)$ & $1(7.7)$ & $1(7.7)$ \\
\hline Puerto Rico or other US territory & $5(13.2)$ & $2(28.6)$ & $0(0)$ & $3(23.1)$ & $0(0)$ \\
\hline Mexico & $21(55.3)$ & $0(0)$ & $4(80.0)$ & $7(53.8)$ & $10(76.9)$ \\
\hline Dominican Republic & $2(5.3)$ & $2(28.6)$ & $0(0)$ & $0(0)$ & $0(0)$ \\
\hline Ecuador & $1(2.6)$ & $0(0)$ & $0(0)$ & $0(0)$ & $1(7.7)$ \\
\hline Other $^{\mathrm{a}}$ & $5(13.2)$ & $1(14.3)$ & $1(20.0)$ & $2(15.4)$ & $1(7.7)$ \\
\hline \multicolumn{6}{|l|}{ Marital status, $n(\%)$} \\
\hline Married or living with a partner & $21(55.3)$ & $2(28.6)$ & $2(40.0)$ & $7(53.8)$ & $10(76.9)$ \\
\hline
\end{tabular}

hoc comparisons using the Tukey honest significant difference test indicated that the Spanish-speaking females were significantly less acculturated than individuals in the other groups $[\mathrm{F}(3,33)=7.39, \mathrm{p}=0.001]$.

\section{Qualitative Findings}

Focus group participants expressed a variety of opinions regarding genetic testing in response to exploratory questions and follow-up probes, as well as the vignette describing and assessing participants' interest in a genetic test for skin cancer risk. Below and in table 2 we present five common themes and several subthemes consistent with the Diffusion of Innovations model [25]. These common themes were shared across the four focus groups and include knowledge and attitudes, communication and sources of information, anticipated responses, factors that may increase adoption, and barriers to adoption of genetic testing. In the text below we also present any gender-based differences that emerged, illustrating these findings with selected participant quotations. Although we examined the transcripts for language-based differences, no consistent differences emerged and are thus not discussed.

\section{Knowledge and Attitudes about Genetic Testing}

Basic Background Understanding of Genetic Testing

Across all of the focus groups, a common theme emerged in that participants understood the basic ele- 
Table 2. Common themes, subthemes and representative participant quotes

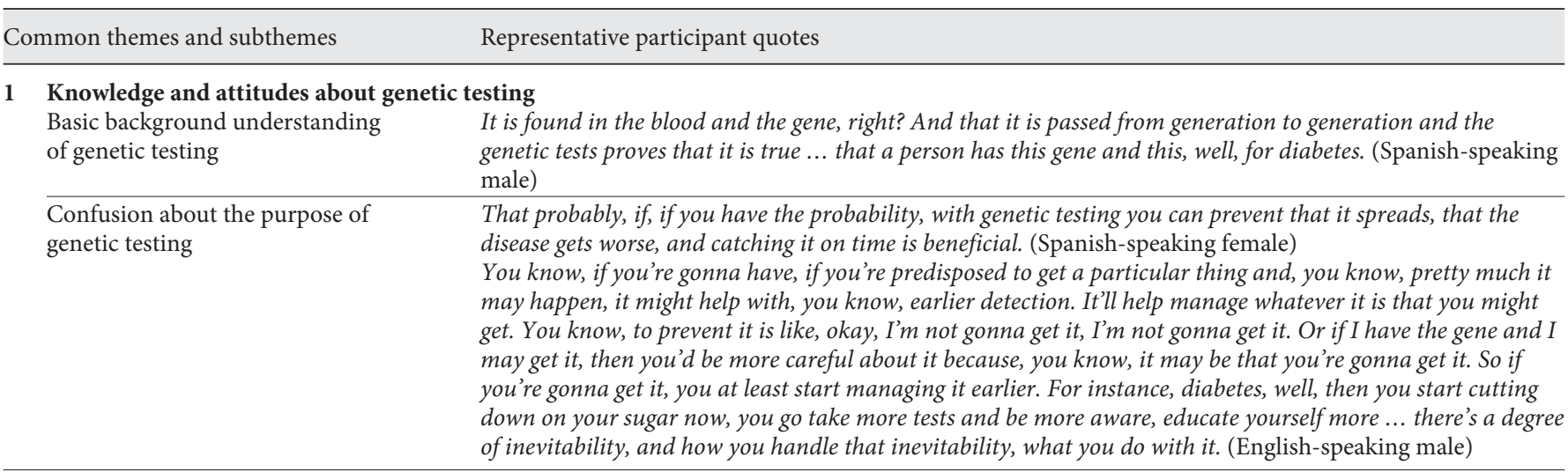

2 Communication and sources of information regarding genetic testing

Frequency of discussion And for genetic testing, that's not something that pops up in a conversation over the dinner table. (English-speaking male)

Information sources $\quad$ Yeah, because if you go on the website and you first check on that you get like an alert and you get scared, and you don't know, you have so many things on your mind, and then so you'd rather go first to your primary doctor. (English-speaking female)

I would go to a doctor to request some advice about my genetics and my partner's genetics. (English-speaking male)

3 Anticipated responses to genetic testing

Interest in genetic testing Wouldn't you want to know? If you're at risk for cancer, wouldn't you want to take that test? (English-speaking female)

Proactive behavioral responses to I would definitely sit down with my doctor and ask her what are the dos and don'ts and to give me a whole results indicating elevated risk rundown of anything that I can do to prevent it, you know. (English-speaking female)

Positive emotional responses to Then it would be as if nothing had happened. (Spanish-speaking male)

results indicating average risk

4 Factors that may increase adoption of genetic testing

Actionable information And if it were inexpensive and widely available, I can see the benefit of everybody getting a baseline and seeing what you're predisposed to and what you should be more careful with. (English-speaking male) And I think that if I had cancer I would do the tests to see if my children also, if they can inherit it from me. So they ... would do genetic tests to my children to see if they can get it. (Spanish-speaking female)

5 Barriers to adoption of genetic testing Misuse

And also, what's going to happen with the information, who's going to have access to that. (English-speaking male)

Personal utility That if you find out something is wrong with you, then your family members might have it and they might have to get that genetic testing too... That's a drawback, in a way. And then, you know, like maybe good because they need to, you know, have it done. (English-speaking female)

Adverse emotional responses Better yet, it is the fear of knowing that one has it and so it makes you more depressed. (Spanish-speaking female)

It depends on what you hear back, you know. It might be like that death sentence, how are you gonna handle knowing, okay? Would that trigger suicidal ideation, for instance? (English-speaking male)

Practical barriers Many people are not really like to make use of that resource because they do not have enough money ... And so they say to themselves, okay, I may have that illness but for now I have to put food on the table for my children, so I cannot ... and they do not do it. (Spanish-speaking male)

That we won't be able to ... Like we won't be able to communicate. (Spanish-speaking female)

Please see text for descriptions of gender-based differences in the subthemes and representative participant quotes.

ments of genetic testing. Participants described genetic testing as a type of blood test that is related to heredity and family history, illnesses that can be passed down from one generation to the next, and genes that run in families and in a family tree.
Some notable differences in understanding emerged across the male and female groups. First, there was a difference in participants' awareness of the health applications of genetic tests. Male participants cited a more diverse set of health applications of genetic tests, including 
cancer, Alzheimer's disease and diabetes, as described in the following quote:

When I think of genetic testing is when it's used to see if someone has a higher risk for certain illnesses. For example, some are at a higher risk for skin cancer because some people don't have the same complexion as others ... and not just that but anything else like Alzheimer's disease ... And if they have a relative that has it, you have a higher chance of having it as well. (Spanish-speaking male)

Male participants were also more likely to discuss genetic testing applications beyond health such as crime and forensics. As one participant stated:

Like when they are talking about a crime or something like that ... It's always a total pantomime, um, they take a drop of blood and in 3 hours they already have all the information. (Spanish-speaking male)

Second, although the male and female groups each noted that genetic testing had relevance to reproduction, their focus in this domain differed. Female participants primarily described the use of genetic tests in the context of pregnancy and amniocentesis, as demonstrated by the following quote:

That test that [she] took, I'm taking because I have 44 years old, and it's very hard because you pregnant, right? So if the doctor put the big needle inside, in first to stomach, your skin and coming inside to the baby and taking liquid, it's very hard because you see everything that happen. And it's so scary. (English-speaking female)

Male participants, on the other hand, discussed how genetic testing could have implications for paternity and child support.

The only thing I can think of is paternity, right? A lot of people do the test, like, to know who is actually the father. You see that all the time even on TV, right? (Spanish-speaking male)

Confusion about the Purpose of Genetic Testing

A few participants believed that a genetic test was something that their doctor could or would simply order while doing other blood work, such as that to assess cholesterol or blood sugar levels. All of the focus groups expressed some degree of uncertainty regarding the purpose of genetic tests and the information these tests may provide. As highlighted in table 2 and the quotes below, participants expressed general confusion about whether genetic tests were used to predict a probabilistic risk for a disease, used in response to symptoms in order to diagnose or screen for an existing illness such as cancer, or used to guide disease treatment based on an ability to change DNA or how it functions.

Latinos' Genetic Testing Attitudes
I think that if I went to the doctor and felt, like, some symptoms, all that, and if the doctor told me, we have to do a genetic test to see if you have cancer ... I think that I would do it then. (Spanishspeaking female)

I mean I know that there - you can - there's some genetic normalities [sic] that you can look for in people in order to maybe change the genetic code and treat it somehow. (English-speaking male)

A notable gender-based difference emerged regarding participants' awareness of limited knowledge about genetic testing. As exemplified in the following quote, the female focus groups acknowledged that genetic testing was a topic that they knew little about. However, the male focus groups did not raise this as an issue.

We hear it a lot on television but we don't pay much attention. (Spanish-speaking female)

\section{Communication and Sources of Information regarding Genetic Testing}

Frequency of Discussion

Although a few participants noted that genetics had been a topic discussed as part of their formal education, all participants stated that genetic testing was not a typical topic of conversation among their families or friends. As a result, participants noted few, if any, prior discussions about genetics and genetic testing among members of their social networks.

\section{Information Sources}

Participants identified multiple sources that they could use to obtain information about genetic testing. Common information sources included the Internet and websites such as Google and WebMD, and media including radio and television. Female participants also cited libraries as useful information sources. Participants expressed a preference for speaking to those who are likely to be authorities on the topic of genetic testing, and were most interested in seeking information from hospitals and doctors, including their primary care providers.

\section{Anticipated Responses to Genetic Testing}

Interest in Genetic Testing

Participants in all four focus groups acknowledged that they had not previously considered genetic testing for themselves. Upon being presented with the vignette, which included specific details about a blood-based genetic test for skin cancer risk, participants generally expressed enthusiasm and high levels of interest in receiving such testing. However, a caveat was noted in some of the focus groups: Participants believed that if they did not 
have a family history of skin cancer, they would be less interested in pursuing this type of genetic testing. As one man explained:

I'm actually leery about the examinations that aren't of any significance. Not that that's not significant. I'm just saying if I'm not symptomatic and my family has no history of it, I don't see the need to go above and beyond to search for something that may or may not be there. (English-speaking male)

Proactive Behavioral Responses to Results Indicating Elevated Risk

Participants in all of the groups described how they would respond if they learned that they had an elevated skin cancer risk as a result of taking the genetic test described in the vignette. Participants frequently stated that their response would be to actively seek out information from their doctors or dermatologists regarding skin cancer prevention strategies and treatment options.

A gender-based difference emerged in the anticipated responses that participants described. Male participants tended to discuss health behavior changes that they would consciously make to prevent developing skin cancer or to stop the progression of disease, as exemplified with the following quote:

Well, with skin cancer they do tell you, no? If you are at risk, no? That would be good, no? Things I would not do. I would not go out ... I mean, I would not expose myself to the sun for long periods of time ... to prolong you life. (Spanish-speaking male)

Among the female groups, participants discussed how they would use this risk information to help their families and care for their children. One woman described such an anticipated response to a positive genetic test result:

I feel that if I came out positive I would tell my relatives so that they also do the test ... Also so that we are able to take care of our kids and avoid giving them whatever caused us harm. (Spanishspeaking female)

Positive Emotional Responses to Results Indicating Average Risk

Participants in each group also described their anticipated reactions to learning that they did not have an increased skin cancer risk as a result of taking the genetic test described in the vignette. Participants anticipated that in this situation, they would feel joy or happiness, and experience a celebration of the good news and of being able to return to how they normally live their lives.

\section{Factors That May Increase Adoption of Genetic}

Testing

Actionable Information

As previously noted, most participants had not thought about getting a genetic test prior to their participation in the focus group. However, many participants cited the possibility of learning actionable health information as the primary reason that one would consider testing. Participants anticipated that genetic testing could provide information that would allow one to change their health behaviors or engage in new behaviors in order to prevent disease, and to gain information that would allow one to detect a disease at an earlier stage when available treatments may be more effective. In addition, participants valued the possibility of learning information that could be used to help or protect the health of their children.

\section{Barriers to Adoption of Genetic Testing}

Misuse

A majority of participants expressed concerns about the possible misuse of genetic information or biological samples that could be obtained through genetic testing. These concerns suggested a sense of scientific or medical distrust. However, there were gender-based differences in the specific types of abuses that participants described. The possibility of stealing or selling blood was a concern raised in a female focus group, as noted by one woman:

If I went to a doctor that is, that is, like, certified. That is, a doctor, I mean, that I can trust, I feel that I would do it. I would trust him. But if I go and feel like they have a campaign, or like those spaces that they put out in the street, and they tell you that they are going to do the genetic test, I feel that that would scare me because maybe, maybe, they get blood to do other studies. Like they do with experiments. Better yet they can eh ... deceive you. They get your blood and do other experiments and that would scare me. (Spanish-speaking female)

In the male focus groups, fears regarding insurance and discrimination were more commonly expressed. As one man explained:

What I've seen on TV, you know, how genetic testing and how insurance companies would love to get their hands on that information, you know, the main fear of the general population that they may lose benefits or be denied insurance because, you know, they're the ones that are gonna lay out a lot of money if you get sick or die of this - you know, and it's also life insurance. It's not just health insurance companies, but also life insurance companies, if they know that someone might die of, not only skin cancer, but a disposition, predisposed to, you know, heart disease or anything that would kill you prematurely, or a problem with like diabetes,
Hamilton/Shuk/Arniella/González/Gold/ Gany/Robson/Hay 
with all the complications that that has, you know, they wanna and all of the sudden like, you know, your family wants to insure you for a half a million dollars. (English-speaking male)

\section{Personal Utility}

Participants were also concerned about the broad implications of information that could be learned through a genetic test. Beyond having clinical utility in terms of affecting their own health or utilization of healthcare, participants expressed concerns about how genetic test results may ultimately influence how they and their families live their lives.

Although not expressed among the female focus groups, participants in the male focus groups tended to be most concerned with the behavioral and lifestyle implications of genetic risk information. Such concerns about how genetic risk information might interfere with their normal ways of life are highlighted in the following quotes:

Well, changes in the habits. Let's say that you like ice cream, no? And what if they told you that you cannot have ice cream anymore? It is a drastic change for a person who is used to doing something, no? (Spanish-speaking male)

Right, you would live your life differently, as opposed to someone who didn't know anything and just lived carefree. It takes away the joy of life. (Spanish-speaking male)

\section{Adverse Emotional Responses}

Both male and female participants noted that emotions such as depression or fear could be experienced when someone undergoes genetic testing. Participants believed that such adverse emotional responses were a likely consequence of receiving negative or life-altering genetic test results, and thus served as a primary disadvantage of genetic testing.

\section{Practical Barriers}

A number of practical barriers to the adoption of genetic testing were discussed among the focus groups, including finances (related to both the costs of genetic testing and of necessary follow-up medical care), a lack of access and knowledge about where to get a genetic test, a lack of a family history of disease, and difficulties related to language proficiency and educational level.

Differences emerged in the male and female focus groups' discussions of the practical barriers to genetic testing. Specifically, female participants raised concerns about the physical process and associated pain of genetic testing. As one woman stated:

If I don't feel the symptoms there is no need to do it because it must be painful. (Spanish-speaking female)
Religious beliefs were also noted as a practical barrier to testing, although this was only noted by one female participant:

Basically, I'm not talking about like my background, which is Mexican. Most of the Mexicans I know, they're Catholic, and most of them, they don't like - like they're like very, well, 'Oh, God is gonna punish me if I do that', and they don't wanna take the risk to go and do the test. (English-speaking female)

Among the male focus groups, employment-related barriers were noted, such as working long hours and being unable to take time off from work to seek genetic testing. One man described the specific employment-related challenges other Latinos could encounter:

Employment, there's employment that doesn't provide healthcare benefits, like if you're sick you might lose your day, if you go to the doctor you don't get paid. So that could be a barrier ... Or I work six, seven days a week and I don't know of this. (Englishspeaking male)

Male participants also mentioned that age could be a barrier to the use of genetic testing, because younger individuals may not believe that genetic testing is relevant to their lives. As one man explained:

Age of the person. Anybody below 30 is not gonna care because they don't. (English-speaking male)

\section{Discussion}

Among male and female Latinos with primarily low levels of acculturation, we identified specific beliefs and attitudes about genetic testing in general, as well as genetic testing for skin cancer risk in particular. Novel gender-based differences were also observed, although these findings should be interpreted cautiously given that fewer males than females contributed their perspectives to this study.

The results indicated that most participants understand the basic elements of genetic testing, recognizing that such tests are related to health, heredity and family history. Some gender-based differences in awareness did emerge. Male participants described a greater variety of disease contexts in which genetic testing may be relevant than did female participants. Furthermore, whereas both genders were aware of genetic testing related to reproduction, females focused on their experiences in the prenatal testing context while males noted the existence of genetic testing for determining paternity. Issues related to pregnancy and parenting may have been particularly salient to participants given that the sample was recruited from parenting support and child/mother interaction groups 
at the community health organization. Nonetheless, this high level of basic awareness was an unexpected and welcome finding, because low levels of awareness of clinical genetic testing have been identified among Latinos in prior population-based and community studies [10-12].

However, there does appear to be a strong need for additional information about genetic testing among Latinos of generally low acculturation, as participants expressed a fair degree of uncertainty about the purpose of genetic testing and the scope of health information that these tests can provide. Many participants of both genders expressed confusion about whether genetic tests were used for diagnostic or predictive purposes, or whether genetic testing may allow for alterations in the structure or functioning of genetic material. Whereas male participants rarely discussed limitations in their knowledge, female participants were acutely aware of their limited understanding of genetic testing, with some admitting that they paid little attention to information about this topic when it was covered in the media or other sources. It is not clear why the Latinas in our sample had previously ignored or avoided such information. It may be that these participants had perceived messages regarding genetic testing as confusing, irrelevant or upsetting, although additional studies are needed to explore these possibilities.

The results also suggested that male and female Latinos of low acculturation had little knowledge of the existence of DTC genetic tests. Although DTC genetic testing is frequently advertised via the Internet $[1,50]$ and study participants cited the Internet as a top information source, none of the participants explicitly described or referenced DTC genetic tests. This finding is consistent with past studies that have found generally low levels of awareness of DTC genetic testing among Latinos as well as other racial and ethnic groups [51, 52]. Given our observation that Latinos of low acculturation have limited understanding of the scope of health information provided by genetic testing, these individuals may benefit from educational materials that help them evaluate and interpret the complex and sometimes misleading messages regarding DTC genetic tests [50].

Study participants' discussions regarding their communication experiences and information sources reveal possible venues for addressing Latinos' information needs about genetic testing. Latinos' social networks do not appear to be a common source of genetic testing information, given that such conversations were considered to be private or of a sensitive nature and were infrequently reported. Participants anticipated initially turning to the Internet and media, yet expressed some reservations about these sources, consistent with research demonstrating that Latinos who are less comfortable with English are less trusting of these health information sources than are Latinos of greater acculturation [53]. Participants noted a clear preference for seeking information from a perceived authority on the topic of genetic testing. Trusted doctors, including their primary care providers, were seen as such authorities who could provide reliable information. Thus, it may be particularly helpful for primary care providers to initiate discussions on the topic of genetic testing with their patients, with an effort made to clearly explain the appropriate indicators for testing, the kinds of knowledge generated from testing and the limitations of testing. Such conversations could help address the confusion regarding genetic testing expressed by our study participants, and may be increasingly beneficial given the wide variety of tests available to healthcare consumers (both clinically available and DTC tests). Conversations initiated in the reproductive context by trusted healthcare providers may also allow for the effective dissemination of accurate information about genetic testing. Such approaches involving the active provision of information may be particularly effective for Latinos with lower levels of acculturation, as past work has demonstrated that both English- and Spanish-speaking Latinos report less active cancer information seeking than non-Latinos, and Spanish-speaking Latinos report more negative and challenging information seeking experiences [54].

Although most participants had not previously considered undergoing genetic testing, participants expressed high levels of interest when the vignette about a genetic test for skin cancer risk was provided. Prior studies have found similarly high levels of receptivity and interest in genetic tests for cancer and other disease risks among Latinos [12, 15-20]. When asked to imagine their reactions to results indicating higher skin cancer risk, participants frequently anticipated taking proactive measures. For male participants, these measures tended to include adopting health-promoting behaviors or ceasing risky behaviors. However, female participants were primarily concerned with sharing and addressing the implications of these results with their families and children. Interestingly, when asked as part of the vignette to imagine a scenario in which they received genetic test results indicating an average risk of developing skin cancer, participants tended to focus on the quick emotional relief provided by such information. Participants did not describe ways in which this information would affect their existing heath behaviors, such as serving as a cue to re-
Hamilton/Shuk/Arniella/González/Gold/ Gany/Robson/Hay 
duce ongoing sun protection efforts. However, the responses of Latinos to the actual receipt of genetic feedback for skin cancer risk need to be examined with future studies, because findings are mixed as to whether nonpathogenic skin cancer genetic testing results can lead to false reassurance and reduction in sun protection behaviors [55-60].

Participants strongly believed that the primary reason to undergo genetic testing would be to receive actionable information that could improve their health and the health of their families. However, they also recognized that by receiving such actionable information, they might be forced to make unwanted or difficult lifestyle changes. Thus, the possibility of receiving actionable health risk information was perceived as both a benefit of genetic testing and a barrier to seeking testing. The extent to which individuals perceive actionable genetic risk feedback as an advantage or disadvantage of testing is likely dependent on a number of psychological factors that were not explored in this study, such as their readiness to change their behavior, behavioral self-efficacy and perceived efficacy of a behavior for reducing disease risk [61, 62]. Participants also believed that the possibility of experiencing severe and adverse emotional responses to test results could serve as a barrier to testing. Studies in the context of both genetic testing for hereditary cancer syndromes [63-65] and genomic testing for multiple common diseases $[66,67]$ indicate that strongly negative, long-term emotional responses to test results are rare. People are generally poor at anticipating their emotional responses to future events (i.e. 'affective forecasting') [68, 69], and Latinos considering genetic testing may benefit from information about typical emotional responses to test results as well as the availability of appropriate supportive resources.

Additional barriers to the adoption of genetic testing were identified, some of which could be addressed with future educational and intervention efforts. Participants described language barriers, which could interfere with both doctor-patient communication and with the acquisition of information about the process and availability of testing. Participants also noted that they and other Latinos may be worried about the potential misuse of genetic information and biological samples, with specific concerns expressed by men and women. Male participants discussed the possibility of discrimination, particularly in the context of health or life insurance. A female participant expressed concerns related to medical mistrust and the possibility of doctors stealing blood from patients, and others were worried about the possibility of experi-

Latinos' Genetic Testing Attitudes encing physical pain. Offering information in both English and Spanish that follows the principles of clear communication [70] and provides details about a healthcare provider's practices regarding privacy as well as the scope of legal protections, such as the Genetic Information Nondiscrimination Act of 2008 [54], may help address these concerns. Furthermore, although our vignette only described a blood-based genetic test and we did not assess attitudes regarding alternative biospecimens, it is possible that using buccal swabs or saliva as opposed to blood draws to obtain genetic material for testing may be better tolerated among this population. Practical barriers, including limited financial resources, and among men, employment-related difficulties, were also discussed. Overcoming such barriers may require more complex, multilevel interventions that provide affordable genetic testing and follow-up cancer screening in medical practices with extended hours.

\section{Limitations, Strengths and Future Directions}

The qualitative study design allowed for an in-depth, thorough analysis of the attitudes and beliefs of a small sample of Latinos residing in New York City. However, it is not known to what extent these findings reflect the full range of Latinos' perspectives regarding genetic testing and may be generalizable to the broader Latino population, a group which is diverse in terms of sociodemographics and culture. For example, differences in health outcomes have been reported based on country of origin [71], and it is possible that perspectives about health implications of genetic testing could also differ in notable ways that were not captured in this analysis. We aimed to recruit Latino participants of primarily low acculturation levels, as their perspectives about genetic testing have been infrequently evaluated. Given that the majority of this sample reported lower levels of education and income, it is not possible to disentangle the effects of socioeconomic status from Latino ethnicity on participants' attitudes. It is also important to note that the Englishspeaking male participants were fairly acculturated and reported higher levels of education and income than those in the other focus groups, and that more females than males participated in the focus groups. It is therefore possible that the observed gender differences are due in part to these differences in the education and acculturation levels of the male and female participants, or to the sampling of a greater number of females' perspectives. Nonetheless, this is one of the first investigations to evaluate the attitudes of both male and female Latinos regarding genetic testing, and as such provides a foundation for 
the formulation of novel hypotheses and the development of interventions designed to promote informed decision-making about genomic medicine advances in this population.

Our results suggest that primary care provider-delivered messages may be particularly acceptable to Latinos of lower acculturation. Yet, existing research suggests that primary care providers may not be fully prepared for the task of educating their patients about genetic testing and genomic medicine [72]. Thus, both providers and patients could benefit from educational and communication interventions that provide accurate information in a culturally competent manner. Such targeted interventions may help address the challenges of communicating complex concepts about genetic information (e.g. incomplete penetrance, multifactorial etiology of disease, uncertainties about the clinical validity and utility of tests), challenges that may be pronounced for Latinos of lower acculturation. For example, we found that study participants were much more interested in the prospect of genetic testing once a real-life vignette about testing for skin cancer risk was provided. Future investigations could test whether educational messages that provide narratives with concrete, personalized descriptions of genetic testing and genetic risk information are more effective in promoting comprehension, interest and the consideration of testing. Furthermore, targeted messages could be developed that reinforce this population's existing accurate beliefs about genetic testing (such as the beliefs that testing may be unnecessary when a family history of disease is absent or when testing cannot provide actionable information), while simultaneously correcting their inaccurate beliefs (such as the beliefs that genetic testing changes one's DNA, is painful or extremely distressing). Intervention efforts could also be developed that address gender-specific values and concerns, such as the implications of results for family, health-related behaviors and lifestyle changes.

\section{Conclusions}

Genomic medicine has created tremendous opportunities for identifying disease risk and adopting clinical and behavioral strategies to improve health. The present study highlights some of the specific beliefs regarding genetic testing held by male and female Latinos of lower acculturation. These findings suggest current information needs in this population, as well as specific concerns and barriers that may interfere with informed decision-making and the adoption of genetic testing and other advances in genomic medicine. Developing targeted, culturally competent educational and intervention strategies that address both shared beliefs and gender-based values and preferences will help ensure that Latinos of lower acculturation have the opportunity to reap the health benefits of these advances.

\section{Acknowledgments}

This work was supported by the Memorial Sloan Kettering Cancer Center Survivorship, Outcomes, and Risk 2012 Goldstein Award (principal investigator: J.L.H.), and by a National Institutes of Health Support Grant (NCI 2 P30 CA08748-48), which provides partial support for the Behavioral Research Methods Core Facility used in conducting this investigation.

\section{Disclosure Statement}

The authors have no conflicts of interest or financial interests to disclose.

\section{References}

1 Bellcross CA, Page PZ, Meaney-Delman D: Direct-to-consumer personal genome testing and cancer risk prediction. Cancer J 2012;18: 293-302.

2 United States Census Bureau: Facts for features: Hispanic heritage month 2014: Sept. 15-Oct. 15. US Census Bureau News, 2014. http://www.census.gov/newsroom/facts-forfeatures/2014/cb14-ff22.html.

3 Smith JC, Medalia C: Health insurance coverage in the United States: 2013. United States Census Bureau, Current Population Reports, P60-250. Washington, DC, U.S. Government Printing Office, 2014. https://www.census.
gov/content/dam/Census/library/publications/2014/demo/p60-250.pdf.

4 Blackwell DL, Lucas JW, Clarke TC: Summary health statistics for U.S. adults: National Health Interview Survey, 2012. Vital Health Stat 10 2014;260:1-161.

5 DeNavas-Walt C, Proctor BD: Income and poverty in the United States: 2013. United States Census Bureau, Current Population Reports, P60-249. Washington, DC, U.S. Government Printing Office, 2014. https:// www.census.gov/content/dam/Census/library/publications/2014/demo/p60-249. pdf.
6 Heron M: Deaths: leading causes for 2010 . Natl Vital Stat Rep 2013;62:1-96.

7 Haile RW, John EM, Levine AJ, Cortessis VK, Unger JB, Gonzales M, Ziv E, Thompson P, Spruijt-Metz D, Tucker KL, Bernstein JL, Rohan TE, Ho GY, Bondy ML, Martinez ME, Cook L, Stern MC, Correa MC, Wright J, Schwartz SJ, Baezconde-Garbanati L, Blinder V, Miranda P, Hayes R, Friedman-Jimenez G, Monroe KR, Haiman CA, Henderson BE, Thomas DC, Boffetta P: A review of cancer in U.S. Hispanic populations. Cancer Prev Res (Phila) 2012;5:150163. 
8 American Cancer Society: Cancer facts \& figures for Hispanics/Latinos 2012-2014. Atlanta, American Cancer Society, 2012. http:// www.cancer.org/acs/groups/content/\%40epi demiologysurveilance/documents/document/acspc-034778.pdf.

9 Hall MJ, Reid JE, Burbidge LA, Pruss D, Deffenbaugh AM, Frye C, Wenstrup RJ, Ward BE, Scholl TA, Noll WW: BRCA1 and BRCA2 mutations in women of different ethnicities undergoing testing for hereditary breastovarian cancer. Cancer 2009;115:2222-2233.

10 Wideroff L, Vadaparampil ST, Breen N, Croyle RT, Freedman AN: Awareness of genetic testing for increased cancer risk in the year 2000 National Health Interview Survey. Community Genet 2003;6:147-156.

-11 Thompson HS, Valdimarsdottir HB, Jandorf L, Redd W: Perceived disadvantages and concerns about abuses of genetic testing for cancer risk: differences across African American, Latina and Caucasian women. Patient Educ Couns 2003;51:217-227.

12 Kinney AY, Gammon A, Coxworth J, Simonsen SE, Arce-Laretta M: Exploring attitudes, beliefs, and communication preferences of Latino community members regarding BRCA1/2 mutation testing and preventive strategies. Genet Med 2010;12:105-115.

13 Gammon AD, Rothwell E, Simmons R, Lowery JT, Ballinger L, Hill DA, Boucher KM, Kinney AY: Awareness and preferences regarding BRCA1/2 genetic counseling and testing among Latinas and non-Latina white women at increased risk for hereditary breast and ovarian cancer. J Genet Couns 2011;20: 625-638.

-14 Vadaparampil ST, McIntyre J, Quinn GP: Awareness, perceptions, and provider recommendation related to genetic testing for hereditary breast cancer risk among at-risk Hispanic women: similarities and variations by sub-ethnicity. J Genet Couns 2010;19:618629.

15 Sussner KM, Jandorf L, Thompson HS Valdimarsdottir HB: Barriers and facilitators to BRCA genetic counseling among at-risk Latinas in New York City. Psychooncology 2013;22:1594-1604.

16 Catz DS, Green NS, Tobin JN, Lloyd-Puryear MA, Kyler P, Umemoto A, Cernoch J, Brown $\mathrm{R}$, Wolman F: Attitudes about genetics in underserved, culturally diverse populations. Community Genet 2005;8:161-172.

$\checkmark 17$ Ramirez AG, Aparicio-Ting FE, de Majors SS, Miller AR: Interest, awareness, and perceptions of genetic testing among Hispanic family members of breast cancer survivors. Ethn Dis 2006;16:398-403.

18 Streicher SA, Sanderson SC, Jabs EW, Diefenbach M, Smirnoff M, Peter I, Horowitz CR, Brenner B, Richardson LD: Reasons for participating and genetic information needs among racially and ethnically diverse biobank participants: a focus group study. J Community Genet 2011;2:153-163.
9 Singer E, Antonucci T, Van Hoewyk J: Racial and ethnic variations in knowledge and attitudes about genetic testing. Genet Test 2004; 8:31-43.

20 Jagsi R, Griffith KA, Kurian AW, Morrow M, Hamilton AS, Graff JJ, Katz SJ, Hawley ST: Concerns about cancer risk and experiences with genetic testing in a diverse population of patients with breast cancer. J Clin Oncol 2015; 33:1584-1591.

21 Abraido-Lanza AF, Armbrister AN, Florez KR, Aguirre AN: Toward a theory-driven model of acculturation in public health research. Am J Public Health 2006;96:13421346.

22 Heck JE, Franco R, Jurkowski JM, Sheinfeld Gorin S: Awareness of genetic testing for cancer among United States Hispanics: the role of acculturation. Community Genet 2008;11: 36-42.

23 Sussner KM, Thompson HS, Valdimarsdottir HB, Redd WH, Jandorf L: Acculturation and familiarity with, attitudes towards and beliefs about genetic testing for cancer risk within Latinas in East Harlem, New York City. J Genet Couns 2009;18:60-71.

24 Vadaparampil ST, Wideroff L, Breen N, Trapido E: The impact of acculturation on awareness of genetic testing for increased cancer risk among Hispanics in the year $2000 \mathrm{Na}$ tional Health Interview Survey. Cancer Epidemiol Biomarkers Prev 2006;15:618-623.

25 Oldenburg B, Glanz K: Diffusion of innovations; in Glanz K, Rimer BK, Viswanath K (eds): Health Behavior and Health Education: Theory, Research, and Practice. San Francisco, Jossey-Bass, 2008, pp 313-333.

26 Pollitt RA, Clarke CA, Swetter SM, Peng DH, Zadnick J, Cockburn M: The expanding melanoma burden in California Hispanics: importance of socioeconomic distribution, histologic subtype, and anatomic location. Cancer 2011;117:152-161.

27 Cockburn MG, Zadnick J, Deapen D: Developing epidemic of melanoma in the Hispanic population of California. Cancer 2006;106: $1162-1168$

$28 \mathrm{Hu}$ S, Soza-Vento RM, Parker DF, Kirsner RS: Comparison of stage at diagnosis of melanoma among Hispanic, black, and white patients in Miami-Dade County, Florida. Arch Dermatol 2006;142:704-708

$29 \mathrm{Hu}$ S, Parmet Y, Allen G, Parker DF, Ma F, Rouhani P, Kirsner RS: Disparity in melanoma: a trend analysis of melanoma incidence and stage at diagnosis among whites, Hispanics, and blacks in Florida. Arch Dermatol 2009;145:1369-1374.

30 Buster KJ, You Z, Fouad M, Elmets C: Skin cancer risk perceptions: a comparison across ethnicity, age, education, gender, and income. J Am Acad Dermatol 2012;66:771-779.

31 Coups EJ, Stapleton JL, Hudson SV, MedinaForrester A, Rosenberg SA, Gordon M, Natale-Pereira A, Goydos JS: Skin cancer surveillance behaviors among US Hispanic adults. J Am Acad Dermatol 2013;68:576-584.
32 Pipitone M, Robinson JK, Camara C, Chittineni B, Fisher SG: Skin cancer awareness in suburban employees: a Hispanic perspective. J Am Acad Dermatol 2002;47:118-123.

33 Robinson JK, Joshi KM, Ortiz S, Kundu RV: Melanoma knowledge, perception, and awareness in ethnic minorities in Chicago: recommendations regarding education. Psychooncology 2011;20:313-320.

34 Rouhani P, Hu S, Kirsner RS: Melanoma in Hispanic and black Americans. Cancer Control 2008;15:248-253.

35 Krueger RA, Casey MA: Focus Groups: A Practical Guide for Applied Research, ed 5. Thousand Oaks, Sage Publications, 2015.

36 Morgan DL: Focus Groups as Qualitative Research, ed 2. Thousand Oaks, Sage Publications, 1997.

37 Morgan DL: Focus groups. Ann Rev Sociol 1996;22:129-152.

38 Patton M: Qualitative Research and Evaluation Methods. Thousand Oaks, Sage Publications, 2002.

39 Horowitz CR, Brenner BL, Lachapelle S, Amara DA, Arniella G: Effective recruitment of minority populations through community-led strategies. Am J Prev Med 2009;37 (6 suppl 1):S195-S200

40 Morgan DL: The Focus Group Guidebook. Thousand Oaks, Sage Publications, 1998

- 41 Lara M, Gamboa C, Kahramanian MI, Morales LS, Bautista DE: Acculturation and Latino health in the United States: a review of the literature and its sociopolitical context. Annu Rev Public Health 2005;26:367-397.

42 Marin G, Sabogal F, Vanoss Marin B, OteroSabogal R, Perez-Stable EJ: Development of a short acculturation scale for Hispanics. Hisp J Behav Sci 1987;9:183-205.

43 Bernard HR: Research Methods in Anthropology: Qualitative and Quantitative Approaches. Lanham, AltaMira Press, 2006.

44 Boyatzis RE: Transforming Qualitative Information: Thematic Analysis and Code Development. Thousand Oaks, Sage Publications, 1998.

45 Green J, Thorogood N: Qualitative Methods for Health Research. London, Sage Publications, 2004

46 Patton MQ: Enhancing the quality and credibility of qualitative analysis. Health Serv Res 1999;34:1189-1208.

47 Creswell JW: Qualitative Inquiry and Research Design: Choosing among Five Traditions. Thousand Oaks, Sage Publications, 1998.

48 Morse JM, Barrett M, Mayan M, Olson K, Spiers J: Verification strategies for establishing reliability and validity in qualitative research. Int J Qual Methods 2002;1:1-19.

49 Miles M, Huberman A, Saldana J: Qualitative Data Analysis: A Methods Sourcebook. Thousand Oaks, Sage Publications, 2014.

50 Lewis NP, Treise D, Hsu SI, Allen WL, Kang $\mathrm{H}$ : DTC genetic testing companies fail transparency prescriptions. New Genet Soc 2011; 30:291-307. 
51 Langford AT, Resnicow K, Roberts JS, Zikmund-Fisher BJ: Racial and ethnic differences in direct-to-consumer genetic tests awareness in HINTS 2007: sociodemographic and numeracy correlates. J Genet Couns 2012;21: 440-447.

-52 Agurs-Collins T, Ferrer R, Ottenbacher A, Waters EA, O'Connell ME, Hamilton JG: Public awareness of direct-to-consumer genetic tests: findings from the 2013 U.S. Health Information National Trends Survey. J Cancer Educ 2015;30:799-807.

53 Clayman ML, Manganello JA, Viswanath K, Hesse BW, Arora NK: Providing health messages to Hispanics/Latinos: understanding the importance of language, trust in health information sources, and media use. J Health Commun 2010;15(suppl 3):252-263.

54 Genetic Information Nondiscrimination Act of 2008: Public Law 110-233, 122 Stat. 881, 2008. http://www.gpo.gov/fdsys/pkg/PLAW110publ233/pdf/PLAW-110publ233.pdf.

55 Glanz K, Volpicelli K, Kanetsky PA, Ming ME, Schuchter LM, Jepson C, Domchek SM, Armstrong K: Melanoma genetic testing, counseling, and adherence to skin cancer prevention and detection behaviors. Cancer Epidemiol Biomarkers Prev 2013;22:607-614.

56 Christensen KD, Roberts JS, Shalowitz DI, Everett JN, Kim SY, Raskin L, Gruber SB: Disclosing individual CDKN2A research results to melanoma survivors: interest, impact, and demands on researchers. Cancer Epidemiol Biomarkers Prev 2011;20:522-529.
57 Aspinwall LG, Leaf SL, Dola ER, Kohlmann $\mathrm{W}$, Leachman SA: CDKN2A/p16 genetic test reporting improves early detection intentions and practices in high-risk melanoma families. Cancer Epidemiol Biomarkers Prev 2008; 17: 1510-1519.

58 Aspinwall LG, Taber JM, Leaf SL, Kohlmann W, Leachman SA: Melanoma genetic counseling and test reporting improve screening adherence among unaffected carriers 2 years later. Cancer Epidemiol Biomarkers Prev 2013;22:1687-1697.

59 Branstrom R, Kasparian NA, Affleck P, Tibben A, Chang YM, Azizi E, Baron-Epel O, Bergman W, Chan M, Davies J, Ingvar C, Kanetsky PA, van Leeuwen E, Olsson H, Gruis NA, Brandberg Y, Newton-Bishop J: Perceptions of genetic research and testing among members of families with an increased risk of malignant melanoma. Eur J Cancer 2012;48: 3052-3062.

60 Hay JL, Baguer C, Li Y, Orlow I, Berwick M: Interpretation of melanoma risk feedback in first-degree relatives of melanoma patients. J Cancer Epidemiol 2012;2012:374842.

61 Prochaska JO, Norcross JC, Fowler JL, Follick MJ, Abrams DB: Attendance and outcome in a work site weight control program: processes and stages of change as process and predictor variables. Addict Behav 1992;17: 35-45.

62 Witte K: Putting the fear back into fear appeals: the extended parallel process model. Commun Monogr 1992;59:329-349.

63 Hamilton JG, Lobel M, Moyer A: Emotional distress following genetic testing for hereditary breast and ovarian cancer: a meta-analytic review. Health Psychol 2009;28:510518.
64 Aspinwall LG, Taber JM, Leaf SL, Kohlmann W, Leachman SA: Genetic testing for hereditary melanoma and pancreatic cancer: a longitudinal study of psychological outcome. Psychooncology 2013;22:276-289.

65 Heshka JT, Palleschi C, Howley H, Wilson B, Wells PS: A systematic review of perceived risks, psychological and behavioral impacts of genetic testing. Genet Med 2008;10:19-32.

66 Bloss CS, Wineinger NE, Darst BF, Schork NJ, Topol EJ: Impact of direct-to-consumer genomic testing at long term follow-up. J Med Genet 2013;50:393-400.

67 Bloss CS, Schork NJ, Topol EJ: Effect of direct-to-consumer genomewide profiling to assess disease risk. N Engl J Med 2011;364: 524-534.

68 Peters SA, Laham SM, Pachter N, Winship IM: The future in clinical genetics: affective forecasting biases in patient and clinician decision making. Clin Genet 2014;85:312-317.

69 Wilson TD, Gilbert DT: Affective forecasting; in Zanna MP (ed): Advances in Experimental Social Psychology. San Diego, Academic Press, 2003, vol 35, pp 345-411.

70 Zarcadoolas C, Pleasant AF, Greer DS: Advancing Health Literacy: A Framework for Understanding and Action. San Francisco, Jossey-Bass, 2006.

71 Martinez-Tyson D, Pathak EB, Soler-Vila H, Flores AM: Looking under the Hispanic umbrella: cancer mortality among Cubans, Mexicans, Puerto Ricans and other Hispanics in Florida. J Immigr Minor Health 2009;11:249257.

72 McInerney JD, Edelman E, Nissen T, Reed K, Scott JA: Preparing health professionals for individualized medicine. Pers Med 2012;9: 529-537. 